\title{
Hallazgo de monedas califales de Marroquíes Bajos (Jaén)
}

\author{
Alberto Canto García, * \\ Gloria García Ruiz, * \\ Lourdes Ruiz Quintanar*
}

\section{INTRODUCCIÓN}

Este conjunto de monedas apareció en el transcurso de las excavaciones que son objeto de otro artículo en este número en el que se explican las circunstancias del mismo (SERRANO 1997). Está compuesto en su totalidad por 201 monedas de plata, dirhemes, y un lote de fragmentos de las mismas del califato de Córdoba, sin que hayamos detectado la presencia de monedas de otras dinastías.

\section{Composición}

La estructura del hallazgo es similar a la de otros muchos conjuntos de época califal, en tanto en cuanto, recoge materiales de los tres califas del siglo X ('Abd al-Raḥmān III, al-Hakam II y Hišām II, a los que hay que añadir una serie de piezas de Muhammad al-Mahdī y Sulaymān al-Musta'în (Figura 3.1).
Los límites cronológicos del hallazgo son el $330 \mathrm{H} . / 94$ I d.C., para la moneda más antigua y el 405H./I0I4 d.C., para un grupo de piezas, como la última fecha registrada; la abundancia de piezas de esta última fecha y su estado de conservación inducen a pensar que el ocultamiento debió realizarse en unos términos muy cercanos a la última fecha mencionada.

La conformación del hallazgo según los años representados en la Figura 3.2:

La primera fecha registrada de 'Abd al-Raḥmān III es la del año 330H./94 I d.C., y los años representados en el conjunto son casi todos hasta el 350H./96 I d.C., con la salvedad del 332, 335 y 336H./947 d.C., de ceca al-Andalus y el 340H./95 I d.C., de ceca madīnat al-Zahrā. La fecha de arranque es la habitual para los conjuntos de época califal, ya que las emisiones anteriores al citado año son bastante escasas en los hallazgos (CANTO 1986).

\begin{tabular}{|c|c|c|c|}
\hline \multirow[t]{2}{*}{ CALIFA } & \multicolumn{3}{|c|}{ CECAS } \\
\hline & Al-Andalus & M. al-Zahrā' & M. Fās \\
\hline cAbd al-Raḥmān III & 8 & 34 & \\
\hline Al-Hakam II & & 24 & \\
\hline Hišằm II (ler, reinado) & 42 & & 5 \\
\hline Hišām \|I ( $2^{\circ}$. reinado $)$ & 7 & & \\
\hline Muhammad II & 6 & & \\
\hline Sulaymān ( ler. reinado) & 1 & 6 & \\
\hline Sulaymān $(404-405 \mathrm{H})$. & \multicolumn{3}{|c|}{59 (con nombre Sulaymān en anverso) } \\
\hline "Independientes" & \multicolumn{3}{|c|}{7} \\
\hline Falsas de cobre & \multicolumn{3}{|l|}{2} \\
\hline
\end{tabular}

* Departamento de Prehistoria y Arqueología. Univ. Autónoma de Madrid, Campus de Cantoblanco, 28094 MADRID. 
Por su parte la serie de al-Hakam II presenta más lagunas ya que solo llega hasta el año 362 H./972 d.C., faltando monedas de los años 354,36 I y $363-366 \mathrm{H} . / 976$ d.C., Aunque es el califa con menos años de reinado no es menos cierto que su producción anual es muy alta y resulta algo sorprendente este menor número de monedas.

En cuanto a Hišām II, la serie resulta muy homogénea en los años finales, presentando más vacios en la primera década, en la que el vacio de los años 372-376H./986 d.C., y algunos años ausentes fijan las carencias en los años $368,370-379,382,384-386$ y 390H./999 d.C., estando los años finales mejor representados, aunque no aparezca ninguna moneda de su último año del primer reinado, el 399H./I008 d.C. En lo relativo a la ceca de madínat Fās, tan activa en época de Hišsam II, sólo aparecen cinco piezas, siendo cuatro de ellas de los últimos años (entre el 388H./998 d.C., y el $395 \mathrm{H} . / / 004$ d.C.). El aumento progresivo del número de monedas de los últimos años parece lógico al acercarse a la fecha de cierre del ocultamiento del conjunto.

El segundo reinado de Hišāmm II presenta siete monedas entre el $401 \mathrm{H} . / \mathrm{I} 0 \mathrm{I} 0 \mathrm{~d}$ d.C., y el $402 \mathrm{H} . /$ I0 1 | d.C., correspondiendo a este último año cinco ejemplares.

Muhammad II presenta un pequeño lote de seis piezas, cinco de ellas del año 400H./ I 009 d.C.

Lo más llamativo de este conjunto son las monedas que suponen el cierre del hallazgo, es decir, todo el lote de piezas batidas a nombre de Sulaymān al-Musta'în, en sus dos reinados.

Para el primero de ellos todas las piezas, siete, son del año 400H./lo09 d.C., una batida en al-Andalus y seis presentan la ceca de madīnat al-Zahrā. Sin embargo, en el segundo reinado de Sulaymān al-Musta'în, la complejidad de sucesivas emisiones y su diferente aspecto añade alguna complicación a la secuencia.

\section{Las monedas con nombre Sulaymān en el anverso.}

Este grupo de monedas (59 ejemplares a los que se añadirían las 7 monedas asignadas a los llamados "independientes") supone más de un $25 \%$ del total, a lo que debemos añadir que 57 de ellas son del año 405H./IOI 4 d.C, un año con piezas bastante raras y escasas; el estado de conservación de este grupo es muy bueno, reflejando un tiempo de circulación reducido.

El problema principal estriba en la atribución que queramos dar a los nombres que aparecen en la primera área de las monedas. De forma tradicional, durante el califato, este lugar había sido reservado a los nombres de funcionarios (șāhib al-Sikka) que controlaban la producción de moneda (CODERA I878, CANTO 1987, MARTINEZ 1992); en el año 400H./I 009 d.C, tanto en las piezas de Muhammad al-Mahdī como en las de Sulaymān al-Musta'īn (primer reinado), los nombres son los mismos en algunos casos (Ibn Maslama, Ibn Šuhaid, Muhammad) pudiendo pensarse que cumpliesen la misma función mencionada anteriormente.

Sin embargo en el segundo reinado de Sulaymān al-Mustacīn los problemas aumentan: por un lado en los años 40 I-402 H./ I 0 I 0- I 0 I I d.C., este ha sido expulsado de Córdoba, pero acuña en otros lugares, bajo el nombre genérico de ceca "al-Andalus". Cuando se hace de nuevo con el control de Córdoba (y posiblemente desde antes) aparece una serie de piezas que incluyen una galería de nombres en el anverso, de los que desconocemos casi todo. Así se considera que en su segundo periodo califal: "... dividió una parte del territorio de al-Andalus entre los jefes de las tribus beréberes..."; según este reparto correspondió el territorio de Jaén a los banū Birzāl y los banū Yafran, Granada para los Sinhāŷa, Ceuta para 'Alī b. Hammūd y Tánger y Arcila para Qāsim b. Hammūd (AGUIRRE, JIMENEZ, 1979: pp. 180-181; VIGUERA 1994: p. 34).

Las monedas que aparecen en este momento abarcan los años 403H./IOI2d.C. al 407H./ I O I2- I 014 d.C., y los nombres inscritos son los de Sulaymān, Y̧ahwar, Habīb, Hudayr, Qind, Ibn Jalaf, y alguno más de dudosa grafía. 
De ellos, en este hallazgo, están representados Sulaymān, Habīb, Qind e Ibn Jalaf (en dos grafías algo diferentes).

Estos nombres fueron asignados, en su momento por Codera, Vives y Prieto, como pertenecientes a los "Príncipes Independientes" por los siguientes motivos: para Codera la unidad en la sucesión de presencia de los nombres en los anversos queda rota tras la deposición de Hišām Il y el reinado de Muhammad al-Mahdī, indicando la confusión existente en las siguientes emisiones señalando. "...deben suponerse acuñadas en diferentes puntos por los gobernadores que pronto vinieron a declararse independientes..." (CODERA, 1878: pp.79 y 79-8I). Vives, asimismo, realiza la asignación como "independientes" con los mismos argumentos expresados por Codera (VIVES, 1893: p. xxii-xxiv). Finalmente, Prieto realiza una separación de las emisiones atendiendo, además, a criterios de orden estilístico, según las diferencias de estilo de acuñación entre las sucesivas series emitidas a nombre de Sulaymān. Establece una división entre las batidas en los años 400-402H./ I009- I 0 I I d.C. y 403-405H./ I0I2-1014 d.C., con nombres Habīb, Hadir, Ibn Suhaid y Mudrik y el grupo de los años 404-405H./ I0 I3-1014H./ 1009 d.C. (sobre todo este último) con nombres Sulayman, Ibn Jalaf, 'Abd al-Malik y Qind. Considera que la única emisión propiamente de Sulaymān al-Musta'īn, sería la del 404H./ 1013 d.C.,que no lleva nombre alguno en el anverso, por contraposición a las que lo llevan en las mismas fechas y que considera de "gobernadores independientes" (PRIETO, 1926: pp. I05-108).

La revisión más reciente y completa de las piezas de Sulaymān al-Musta'în es obra de Pellicer, quien lleva a cabo una gran compilación de todos los materiales conocidos hasta el momento; en cualquier caso no puede concretar en las atribuciones de los nombres presentes en los anversos, aunque si incluye piezas que permiten extender la cronología hasta el año 407H./I0I6 d.C. (PELLICER, 1984).

Ante esta situación el panorama no es muy claro pero podemos aceptar algunos hechos más concretos: por un lado la realidad de las dos secuencias de las emisiones de Sulaymān al-
Musta'în, diferenciadas por los nombres que aparecen en los anversos. Si aceptamos la propuesta de Prieto y Vives esta primera serie terminaría en torno año 404H./I0I3 d.C., con la última emisión sin nombre en el anverso. La segunda secuencia abarcaría todas las emisiones con nombres desconocidos en el anverso que comienzan en el 403H./IOI2 d.C., (Habïb, Ibn Hudayr e Ibn Jalaf) y tienen un aumento espectacular en los años 404-405H./I 0 I 4d.C., (en los que continuan los anteriores y se unen Sulaymān, 'Abd al-Malik, Qind, Basil y Ŷahwar).

Utilizando la citada argumentación de Prieto y Vives, la ausencia en este conjunto de las monedas batidas a nombre de Sulaymān alMustacīn sin ningún nombre adicional en el anverso (emisión final del año 404H./ I 0 I3d.C.), sugiere (junto con la presencia del grupo de monedas con nombres) que todo este conjunto final posee una unidad de emisión y la posibilidad de haberse acuñado por alguno de los gobernantes locales.

Por el momento no poseemos datos concretos que nos permitan considerar a ninguno de estos nombres como gobernador independiente en Jaén, salvo que en este hallazgo hayan aparecido 57 monedas a nombre del desconocido Sulaymān, máxime si consideramos que solo se registra en la bibliografía una docena de estos ejemplares (sin duda habrá más, pero es un indicio de su relativa rareza). El siguiente punto a tener en cuenta es la función que estos nombres, presentes en el anverso, han desempeñado en otras emisiones del mismo periodo. En su momento Prieto y Vives aventuró que el de Ibn Jalaf pudiera estar relacionado con una familia del mismo nombre que se independizó en Albarracín (PRIETO, 1926: pp.63 y 107).

Lo que resulta evidente es que algunos de estos nombres que aparecen en el anverso de las monedas serán en años posteriores gobernantes de distinta importancia en al-Andalus (caso de 'Alī b. Hammūd, por citar el más importante). De hecho desaparecido Sulaymān al-Musta'în en el 407H./I0I6 d.C., algunos de estos personajes seguirán apareciendo en monedas de fecha posterior; así ocurre con Qind, quien todavía aparece en el 4 I2H./ 02 I d.C., 
en dinares batidos a nombre de Qāsim b. Hammūd (PRIETO 1932: n 34a, p. 158). El hecho de que otros nombres no alcanzaran esa situación no impide pensar que su situación de "independencia" no fuera muy semejante.

En otras emisiones monetarias de este confuso momento aparecen nombres colocados en el mismo lugar del anverso correspondientes a personajes que, sin duda, alcanzaron una situación de independencia en sus territorios correspondientes; es el caso de los eslavos levantinos Mubāraq y Muḍafar quienes emiten monedas a nombre de 'Alī b. Hammūd en el 407H./ I 016 d.C. (VIVES I893: nº. 805-806, pp. I | 5- I |9), pero gozando de una reconocida autonomía.

Por lo tanto este conjunto de piezas de batidas a nombre de Sulaymān al-Musta'în, con nombre Sulaymān en el anverso, es el mayor conjunto de este tipo publicado hasta la fecha. Siendo en su inmensa mayoría del año $405 \mathrm{H}$. / 1014 d.C., suponen un cierre muy ajustado y exacto del ocultamiento.

Las circunstancias que condujeron a la aparición de este conjunto de monedas en los niveles de destrucción de una casa, citados al comienzo, podrían estar en relación con la intervención del eslavo Jayran quien en el 406 H./I0I5 d.C., se apodera de los territorios de Jaén y Murcia (AGUIRRE, JIMÉNEZ 1979, p. 182).

La atribución del Sulaymān (citado en el anverso y desconocido por el momento) a la ciudad de Jaén en estos turbulentos momentos no puede descartarse, aunque deberá ser comprobada y ratificada con más información complementaria.

\section{Estudio de cuños de la serie del año 405H./I 0 I 4 d.C.}

Este conjunto proporciona la posibilidad de realizar un estudio de cuños sobre los ejemplares del año 405H./I0I 4 d.C., a nombre de Sulaymān, que constituyen un grupo muy homogéneo y que, a simple vista, presentaban similitudes notables. Además el estado de conservación de este grupo es bastante bueno, demostración de la escasa circulación de estas piezas antes del ocultamiento; Al tratarse de un tipo de moneda no muy abundante podría resultar interesante la aplicación de esta técnica a este conjunto de monedas.

Las monedas fueron fotografiadas, digitalizadas en un digitalizador DeskScan II y tratadas las imágenes en programas de dibujo (Adobe Photoshop y Freehand), aplicando filtros para el silueteado y reconstrucción de los bordes con el fin de obtener un dibujo de los perfiles de letras y elementos decorativos (ver figura 4). Las imagenes resultantes fueron comparadas entre si, de acuerdo a los grupos decorativos establecidos, para determinar los diferentes cuños que podían existir dentro del conjunto.

Las monedas del año 405H./I 014 d.C. (n's. de catálogo 143 a 199, tipo Vives 797 y Prieto 28d) presentaban tres elementos decorativos diferentes en el anverso, que permitía formar cuatro familias de cuños diferenciados en los anversos (de 22, 28 y 7 ejemplares respectivamente); por el contrario los reversos no presentan decoraciones, siendo todos del mismo tipo epigráfico, aunque con diferentes facturas y estilos, lo que nos ha permitido establecer 2 variantes (ver figura 5).

La comparación nos proporcionó siete cuños para los anversos y 9 para los reversos en el conjunto de 57 monedas. Este número es relativamente bajo aunque hay que considerar que unos 50 ejemplares salen de la combinación de dos parejas de cuños.

La discusión sobre los diferentes modelos de estimación de producción de moneda es ardua y extensa, variando desde los que optan por valores más bajos a los que se decantan por cifras altas. En nuestro caso hemos optado por utilizar una de las fórmulas sencillas que nos permita establecer una magnitud aproximada relativa a la producción estimada de moneda. Hemos aplicado el modelo de Carter (CARTER 1984), habida cuenta de que su aplicación es sencilla y nos puede proporcionar una estimación aproximada fiable. 
Los resultados han sido muy justos, como era de esperar, ya que el número de cuños utilizado en este conjunto es muy escaso en relación con el número de ejemplares de la muestra. Para la familia de 57 ejemplares, siete cuños de anverso y nueve de reverso, significan que se conoce la práctica totalidad de los cuños utilizados, pues la fórmula correspondiente nos situa en 7 cuños para el anverso y 9,34 para el reverso.

Más aleatorio puede resultar el extrapolar las estimaciones de las cifras de moneda acuñadas con esas posibles combinaciones de cuños. En estos casos la discusión sobre los volúmenes son más árduas dadas las diferencias de estimación sobre la cantidad de monedas producidas; utilizando las referencias citadas una estimación entre 10.000 y 15.000 monedas por cuños parace estar dentro de los márgenes razonables. Aplicando este cálculo nos encontraríamos con la siguiente estimación:

Estimación baja 70-90.000 monedas Estimación alta 105-135.000 monedas

En cualquier caso esta cantidad de monedas no es muy elevada, más bien es bastante baja, si la comparamos con las estimaciones de producción que conocemos para otros momentos del califato. Aunque los estudios de cuños sobre moneda andalusí no han sido muy numerosos podemos comparar nuestra información con la de otros estudios.

Un trabajo realizado sobre el año $392 \mathrm{H}$./I00 I d.C., en una población de 83 monedas obtenía unas identificaciones de cuños de 27 y 25 para los cuños de anverso y reverso respectivamente; las estimaciones de producción (aplicando las mismas cifras que hemos usado aqui) cuadriplicarían las cifras (SAENZ-PELLICER 1986). Otro estudio de este último autor (PELLICER 1987), abarcando unos márgenes cronológicos más amplios, también parece mostrar unas tendencias parecidas. Para los años 330H./94 I d.C., y 340H./95 I d.C. se obtenían unos resultados muy superiores (entre seis y diez veces más altos) (CANTO et alii, 1988). Estos estudios se han aplicado sobre monedas califales correspondientes a los momentos álgidos de esta dinastía, cuando las emisiones y el poder económico del califato esta- ban en su esplendor; esto explica, en gran parte, las grandes diferencias halladas entre las identificaciones de cuños y las estimaciones obtenidas a partir de los mismos.

En el caso que nos ocupa este estudio de cuños viene a ratificar lo que los hallazgos y la bibliografía especializada nos sugerían, el escaso volumen de la acuñaciones de Sulaymān alMusta'în, en este periodo, proceso que se debe ir acentuando en los años finales de su reinado; sería importante poder ir extendiendo estos estudios a las otras emisiones de los llamados "príncipes independientes", para establecer si existen o no enlaces de cuños entre las diferentes emisiones. Ello nos permitiría avanzar en la comprensión de la organización de estos conjuntos.

\section{Comparación con otros hallazgos}

La mayoría de los hallazgos califales tienden a terminar en en los años iniciales del siglo $\mathrm{VH}$./XI d.C., resultando difícil que aparezcan abundantes piezas de este conflictivo momento. Una revisión de los hallazgos conocidos nos permite obtener la siguiente perspectiva:

\section{"Tesoro de monedas árabes" (CODERA 1875).}

Fechas límite: 322-4I4H./933-I 023 d.C.

Abundantes piezas de Sulaymān al-Musta'in del $400 \mathrm{H} . / / 009$ d.C., pero sin fechas posteriores.

\section{"Adquisición...Museo" \\ (CODERA 1882).}

Fechas límite: 322-4I4H./933-1023 d.C.

\section{"Tesoro de monedas descubierto en Cuenca" (CODERA 1893).}

Fechas límite: 318-403H./930-1012 d.C.

Contiene veinte y seis monedas de Sulayman, de las cuales veinte y una son del año $400 \mathrm{H}$. / I 009 d.C., tres del 402H./ I 0 I I d.C., y una del $403 \mathrm{H} . / 1012$ d.C.

\footnotetext{
"Tesoro de monedas árabes de Elche" (LAFUENTE 1930).

Fechas límite: 330-410H./941-1019 d.C.

Una única moneda de Sulayman del $400 \mathrm{H}$. /l 009 d.C.
} 
"Tesoro de monedas encontrado en Badajoz" (PRIETO 1934).

Fechas límite: 321-40 IH./933-1010 d.C.

La información existente sobre este importante hallazgo de dinares proporciona tres piezas el 400H.// 009 d.C., de Sulaymān al-Musta'in.

"Tesorillo de monedas de plata del califato cordobés y fatimíes"

(NAVASCUES 1958).

Fechas límite: 322-400H./933-I009 d.C.

Diez y nueve ejemplares del año 400H./I009 d.C., de ceca al-Andalus y madinnat al-Zahrā'.

\section{"Tesorillo de moneda califal"}

(NAVASCUES 1961)

Fechas límite: iii-400H./iii-1009 d.C.

Un único ejemplar del 400H.//009 d.C.

\section{"Hallazgo de Cihuela"}

(NAVASCUES 1961)

Fechas límite: 321-450H./933-1059 d.C.

Recoge cuatro piezas del 400H./I009 d.C., y dos piezas del 404H./I0I 3 d.C., (Vives 796, Prieto 28c) y no registra ninguna del año siguiente; en cualquier caso la fecha de cierre del hallazgo de Cihuela es mucho más avanzada ya que llega claramente a bien avanzado el periodo taifa.

\section{"Tesoro hispano-árabe hallado en Trujillo" (NAVASCUES 1957)}

Fechas límite: 320-407H./932-1016 d.C.

Este hallazgo plantea muchos problemas por la amplitud de los márgenes cronológicos de la diferentes dinastías que están presentes en el mismo; sin duda deben estar agrupados varios conjuntos de distinta cronología. El conjunto de piezas califales presenta unos límites bastante similares a los de otros hallazgos de la misma época.

Ahora bien la única publicación de este hallazgo cita bastantes ejemplares muy interesantes que entran de pleno en fechas cercanas al problema que nos atañe. De Sulaymān al-Musta'în presenta siete ejemplares del 400H./ 1009 d.C, tres del 405H./I 0 I 4 d.C., y una del 407H./I0I 6 d.C.; de los personajes citados como "desconocidos" de la revolución:

$\begin{array}{lcr}\text { Personaje } & \text { Año } & \text { No de piezas } \\ \text { Habīb } & 403 & \text { | V.787, P.20b } \\ \text { cAbd al-Malik } & 404 & \text { | V.79I, P.32a } \\ & 405 & 3 \text { V.792 var., P.32b } \\ \text { Modrik } & 404 & \text { | V.798, P.25a } \\ \text { Sulaymān } & 405 & \text { | V.797, P.28d }\end{array}$

Es el primero que presenta este conjunto de monedas con los nombres de personajes y con fechas semejantes a las de el hallazgo de "Marroquíes" que nos ocupa.

\section{"Tesoro calle Cruz Conde"}

(NAVASCUES 1961a, 1961b)

Fechas límite: 322-435H./933- 1043 d.C.

Este importante hallazgo es de monedas de oro, pero entra de pleno en las fechas más conflictivas del final del califato, la revolución de Córdoba y la aparición de las primeras taifas. Solo presenta dos piezas de Sulaymān del año $400 \mathrm{H} . / / 009$ d.C., pero añade tres monedas de Ibn Jalaf, dos del 405H.// 014 d.C., e Ibn Qind, una del 4|4H./I023 d.C.

"Tesoro de dirhames hallado en Jaén" (RUIZ 1962) Fechas límite: 322-40 IH./933-10 I 0 d.C.

Presenta catorce ejemplares de Sulaymān alMusta'în del año 400H./I009 d.C.

"Tresor de dirhames a SC-J" (PELLICER 1982)

Fechas límite: 318-4I IH./930-1020 d.C.

Este hallazgo presenta un número elevado de piezas del año 400H./l 009 d.C., cuatro de alAndalus y trece de madinat al-Zahrā'.

"Tresoret de moneda àrab LR-P" (PELLICER 1983) Fechas límite: 331-4I8H./942-I027 d.C.

De los hallazgos de época reciente es el que aporta más monedas para el momento que nos interesa ya que presenta piezas del año $400 \mathrm{H} . / / 009$ d.C. (cuatro ejemplares de ceca al-Andalus y otros tres de madinat al-Zahrā') junto con otras cuatro monedas de los años 404, 405, 406 y 407H./I 016 d.C., de ceca alAndalus. 


$\begin{array}{llr}\text { Personaje } & \text { Año } & N^{\circ} \text { de piezas } \\ \text { Sulaymān } & 404 & \text { | V.796 } \\ & 405 & \text { | V.797 } \\ \text { Basil } & 406 & \text { | V. } \\ \text { Yahwar } & 407 & \text { | V. }\end{array}$

"Tesoro califal de"Los Villares" (MARTINEZ 1989) Fechas límite: 33I-400H./942-I009 d.C.

Este hallazgo de pequeño tamaño solo presenta una pieza del año 400H./I009 d.C.

"Hallazgo Colección Santa-Olalla" (CANTO 1990) Fechas límite: 318-440H./930-1048 d.C.

Cuatro monedas del 400H./I009 d.C., y una del 402 y 403H./I 0 I 2 d.c. Un ejemplar dudoso podría ser del 404H./I0I3 d.C.

\section{"Troballa de dirhemes califals a Baena}

(Córdoba)" (NAVARRO 1991)

Fechas límite: 33 I-400H./942-I 009 d.C.

De nuevo diez ejemplares de Sulaymān, todos ellos del 400H./I009 d.C.

"Los Lobicos (Priego de Córdoba)"

(CARMONA et alii 1993)

Fechas límite: 330-402H./94 I- I0I I d.C.

Una única moneda de Sulaymān del año $400 \mathrm{H}$. / 1009 d.C., con nombre de Ibn Maslama.

\section{Metrología}

El estudio metrológico de este conjunto no aporta nada especial para las series de los primeros califas, puesto que ya han sido publicados varios estudios exhaustivos sobre los tres primeros califas de Córdoba, basados en un número muy amplio de ejemplares. Bien es cierto que este conjunto presenta un estado de conservación bastante bueno y la mayoría de las monedas no presenta ningún tipo de alteración o manipulación. Así en el caso de 'Abd al-Rahmān III solo cinco monedas sobre cuarenta y dos presentan dobles perforaciones; una solo sobre veinte y cuatro en el grupo de al-Hakam II; dos ejemplares perforados y uno recortado sobre cincuenta y cuatro de Hišām II; en el resto de las piezas, solo una de lbn Jalaf se encuentra recortada. El grupo de Sulaymān del año $405 \mathrm{H}$., se encuentra en una situación de conservación excelente reflejo del escaso tiempo en circulación.

Justamente este conjunto de monedas de Sulaymān merece una atención especial en lo que atañe a su metrología, dada su rareza, escaso número de monedas publicadas y ser este el lote más numeroso conocido, además de su buen estado de conservación. Solo se ha realizado un estudio metrológico sobre monedas de este periodo y fue realizado por Pellicer sobre un conjunto de monedas de Sulaymān al-Musta'în de los años 400-407H./I 009- 1016 d.C., sin establecer diferencias entre los años (PELLICER 1984, p. I56-160).

Los resultados de las monedas de este hallazgo son los siguientes (Figura 6):

Número de ejemplares

$\mathrm{N}=57$

Peso Medio

$x=2,99$

Desviación típica

$\mathrm{S}=0,53$

Coeficiente de variación

$V=18 \%$

Peso máximo

4,50 grs.

Peso mínimo

2, 10 grs.

El peso medio de esta serie parece quedar dentro de los límites habituales y característicos de las emisiones califales, y aunque cerca de la mitad de las piezas caen dentro de los márgenes entre 2,5 I y 3,30, aparecen también desviaciones de pesos en los extremos respectivos.

\section{Fragmentos}

El número total de fragmentos del hallazgo de Marroquíes Bajos (Jaén) es de 307, de los cuales sólo cuatro pudieron ser fechados, uno adscrito a al-Hakam II del año 354H./965 d.C, y tres a Hišām II de los años 387H/997 d.C., $389 H . / 998$ d.C y 392 H./ I 00 I d.C. Por tanto no podemos confirmar si los fragmentos pertenecen a los primeros años del hallazgo o a los años finales, ni si el número de ejemplares por año es similar al de las monedas completas.

Para realizar su estudio, los fragmentos fueron pesados individualmente y distribuidos por frecuencias de 0,25 en 0,25 gramos. Con estos 
datos se elaboró el gráfico (Figura 7), en el que se observa que la distribución es muy irregular. Los intervalos $0,26-0,50,0,51-0,75$ y 0,76I,00 son los que presentan mayor número de ejemplares, suponiendo aproximadamente, entre los tres, el $75 \%$ del total de los fragmentos. Esta proporción es similar a la que presentan los fragmentos del hallazgo califal de "Haza del Cármen", estudiado por G. García Ruiz y L. Ruiz Quintanar (1996 en prensa).

Por otro lado los fragmentos fueron clasificados de acuerdo con la propuesta del citado artículo, que asigna a cada fragmento un código compuesto por una letra en función del aspecto de la moneda, seguida de un número del I al 7 en función del tamaño del fragmento. De esta forma la clasificación quedaría como resumimos a continuación (Figura 8 ):

\section{A. Monedas que presentan un ligero daño} en su borde.

BI. Monedas que presentan un sólo corte en su borde y que no abarca más allá del espacio entre éste y la primera línea exterior de la orla

B2. Monedas que presentan uno o más cortes, de dimensiones mayores que las anteriores, en su borde y que llegan a la primera línea exterior de la orla

B3. Monedas que mantienen más de la mitad de la moneda, pero los cortes han traspasado la primera línea exterior de la orla.

B4. Fragmentos que presentan un corte perfectamente lineal y que coincide aproximadamente con la mitad de una moneda completa.

B5. Fragmentos que son más pequeños que la mitad de la moneda y mayores que un cuarto.

B6. Fragmentos que son 1/4 de la moneda.

B7. Fragmentos más pequeños que 1/4 de la moneda.

Atendiendo a esta clasificación el hallazgo de Marroquíes Bajos presenta una abundancia mayor de fragmentos que equivaldrían a I/2 (B3, B4) y un $1 / 4(B 5, B 6)$ de dirham. Mientras que los fragmentos identificables como $3 / 4$ de dirham aparecen en menor proporción, si bien hay que tener en cuenta que algunos de estos últimos han quedado incluidos dentro de las piezas completas al presentar fecha y ceca legibles.
En cuanto a su aspecto encontramos fragmentos de varias formas que también vendrían a confirmar lo propuesto para el hallazgo de Haza del Carmen. Así, el hallazgo de Marroquíes Bajos presenta las formas que fueron definidas como "segmentos de orla", "orla central" o "F" y "regulares".

La aparición de los fragmentos junto a las monedas completas y las características del hallazgo inducen a pensar que el conjunto forma parte del circulante en el momento de la destrucción de la vivienda; esto confirmaría el uso de los fragmentos de moneda como parte del circulante de uso diario, tal como ocurre en otros hallazgos.

\section{CONCLUSIÓN}

Este hallazgo es bastante semejante a otros de época de finales del califato, pero su especial interés radica en la presencia de un número extraordinariamente alto de monedas de los cuatro últimos años de las emisiones de Sulaymān al-Mustaîn, y sobre todo del año 405H./I 014 d.C. Hasta la fecha es el conjunto más numeroso de este año publicado y el estudio de sus cuños y combinaciones decorativas nos ha proporcionado una información bastante completa sobre esta serie. La reducción del volúmen de emisión parece clara en este momento y es de esperar que otros hallazgos nos permitan comprobar la distribución de este tipo de monedas para poder ir confirmando su posible atribución a lugares geográficos concretos, asi como la identificación más precisa de los personajes "desconocidos" que figuran en sus áreas.

\section{CATÁLOGO}

Está organizado por la secuencia cronológica de los gobernantes. Cada moneda presenta los siguientes datos por orden: $\mathrm{N}^{\circ}$ de orden, fecha en años de la Hégira, peso (en gramos), módulo (en milímetros), referencia bibliográfica según Vives (1893), Prieto (1926), Miles (1950) y Frochoso (1995). Las alteraciones en las monedas se definen según el siguiente código: R (rota), P (perforación, más el número de las mismas). 


\section{'Abd al-Raḥmān III (300-350/9|2-96I) \\ Ceca al-Andalus}

$330 \quad 2,78 \quad 24 \quad$ V.396, M.217, F. Inédita. (Fig. 9)

Hasta la fecha todos los ejemplares emitidos en el año 330H./94I d.C., siendo șāhib al-Sikka Qāsim b. Jalid, se ajustaban a un modelo decorativo, con una única excepción (CANTO 1986, FROCHOSO 1995). Esta pieza supone una variante nueva en los tipos decorativos de este año, al no llevar la clásica flor de ocho pétalos sobre la leyenda central de reverso.

$\begin{array}{ll}2 & 330 \\ 3 & 330 \\ 4 & 331 \\ 5 & 331 \\ 6 & 331 \\ 7 & 333 \\ 8 & 334\end{array}$

$\begin{array}{lll}1,90 & 24 & \text { V.396, M.217 b, F.I0 } \\ 2,42 & 24 & \text { V.396, M.217 b, F.I0 } \\ 2,54 & 24 & \text { V.397, M.219 b, F.8 } \\ 2,36 & 25 & \text { V.397, M.219 b, F.9 } \\ 2,60 & 23 & \text { V.397, M.219 b, F.9 } \\ 2,46 & 25 & \text { V.404, M.22I c, F.12 } \\ 3,38 & 29 & \text { V.408, M.222 c, F.I 6/I8. }\end{array}$

\section{Ceca al-Zahrā}

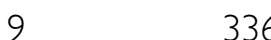

$10 \quad 337$

11337

$12 \quad 337$

$13 \quad 337$

$14 \quad 338$

$15 \quad 338$

$16 \quad 339$

$17 \quad 341$

$18 \quad 342$

$19 \quad 342$

$20 \quad 342$

$21 \quad 343$

$22 \quad 343$

$23 \quad 343$

$24 \quad 343$

$25 \quad 343$

$26 \quad 343$

$27 \quad 344$

$28 \quad 344$

$29 \quad 344$

$30 \quad 344$

$31 \quad 345$

$32 \quad 345$

$33 \quad 346$

$34 \quad 346$

$35 \quad 347$

$\begin{array}{ll}36 & 347\end{array}$

$37 \quad 348$

$38 \quad 348$

$39 \quad 348$

$40 \quad 349$

$41 \quad 350$

$42 \quad 34 X$
$2,66 \quad 28$

$2,40 \quad 24$

$3,96 \quad 26$

$2,70 \quad 26$

$2,64 \quad 24$

$2,56 \quad 24$

$2,34 \quad 23$

$2,20 \quad 22$

$3,00 \quad 22$

$2,76 \quad 22$

$2,14 \quad 22$

$2,74 \quad 21$

$2,70 \quad 22$

$1,54 \quad 23$

$3,08 \quad 22$

$3,12 \quad 22$

$2,46 \quad 23$

$2,74 \quad 22$

$2,94 \quad 22$

$2,72 \quad 24$

$2,66 \quad 23$

$2,94 \quad 22$

$2,60 \quad 23$

$2,72 \quad 22$

$2,28 \quad 24$

$1,94 \quad 23$

$2,16 \quad 23$

$2,44 \quad 22$

$2,10 \quad 23$

$2,66 \quad 22$

$2,34 \quad 22$

$1,90 \quad 22$

$1,70 \quad 22$

$2,52 \quad 21$
V.4I5, M.226 d, F.23/24 var

V.4I7, M.227 d, F.I2

V.417, M.227, F.var

V.417, M.227, F.70 var

V.417, M.227, F.var

V.4I8, M.228, F.12/II

V.418, M.228, F. 59

V.4I9, M.229c, F. 22

V.422, M.23I, F.44 var

V.424, M.232b, F. 7

V.424, M.232, F.36 var

V.424, M.232, F.42

V.425, M.234c, F.7

V.425, M.234c, F.7

V.425, M.234c, F.7

V.425, M.234c, F.7

V.425, M.234c, F.7

V.425, M.234c, F.7

V.427, M.235b, F.6

V.427, M.235b, F.6

V.427, M.235b, F.6

V.427, M.235b, F.6

V.428, M.236a, F.8

V.428, M.236, F.I6

V.440, M.237j, F.35

V.440, M.237j, F.35

V.44I, M.238a, F.4

V.44I, M.238a, F.4

V.443, M.239b, F.7

V.443, M.239b, F.7

V.443, M.239b, F.7

V.444, M.240a, F.5

V.445, M.24I, F.5
P2

P2

P2

P2

P2 


\section{Al-Hakam II (350-366/96I-976) \\ Ceca al-Zahrā}

$\begin{array}{llllll}43 & 350 & 2,24 & 23 & \text { V.447, M.242b, } & \text { F.20 } \\ 44 & 35 I & 2,58 & 25 & \text { V.449, M.243x, } & \text { F.78var } \\ 45 & 352 & 2,96 & 23 & \text { V.450, M.254, } & \text { F.7var } \\ 46 & 352 & 2,86 & 24 & \text { V.450, M.254g, } & \text { F.23 } \\ 47 & 353 & 2,60 & 22 & \text { V.45I, M.245, } & \text { F.36 } \\ 48 & 353 & 2,76 & 22 & \text { V.45I, M.245, } & \text { F.80 } \\ 49 & 353 & 2,40 & 21 & \text { V.45I, M.245x, } & \text { F.9I } \\ 50 & 355 & 2,54 & 21 & \text { V.454, M.247d, } & \text { F.I } \\ 5 I & 335 & 2,78 & 23 & \text { V.454, M.247e, } & \text { F.36 } \\ 52 & 355 & 2,26 & 23 & \text { V.454, M.247u, } & \text { F.89 } \\ 53 & 356 & 2,32 & 21 & \text { V.457, M.248, } & \text { F.II } \\ 54 & 357 & 2,46 & 22 & \text { V.458, M.250g, } & \text { F.27 } \\ 55 & 357 & 2,10 & 22 & \text { V.458, M.250g, } & \text { F.27 } \\ 56 & 357 & 2,94 & 22 & \text { V.458, M.250g, } & \text { F.27 } \\ 57 & 357 & 2,92 & 23 & \text { V.458, M.250k, } & \text { F.28 } \\ 58 & 358 & 2,68 & 23 & \text { V.459, M.25Ij, } & \text { F.19 } \\ 59 & 358 & 2,34 & 23 & \text { V.459, M.25Ij, } & \text { F.I9 } \\ 60 & 359 & 3,18 & 24 & \text { V.460, M.252g, } & \text { F.I6 } \\ 61 & 359 & 3,38 & 23 & \text { V.460, M.252n, } & \text { F.64 } \\ 62 & 360 & 2,66 & 23 & \text { V.46I, M.253h, } & \text { F.19 } \\ 63 & 360 & 2,92 & 24 & \text { V.46I, M.253h, } & \text { F.3I } \\ 64 & 360 & 2,98 & 24 & \text { V.46I, M.253o, } & \text { F.60 } \\ 65 & 360 & 2,66 & 23 & \text { V.46I, M.253, } & \text { F.84 } \\ 66 & 362 & 2,82 & 23 & \text { V.485, M.255, } & \text { F.20 }\end{array}$

Hišām II I er. reinado (366-399/976- I009)

\section{Ceca al-Andalus}

\begin{tabular}{|c|c|c|c|c|c|}
\hline 67 & 366 & 2,42 & 24 & V.498, M.263d, & F.14 \\
\hline 68 & 367 & 2,96 & 24 & V.500, M.264b, & F.8 \\
\hline 69 & 367 & 2,78 & 23 & V.500, M.264b, & F.8 \\
\hline 70 & 369 & 3,60 & 24 & V.504, M.267b, & F.6 \\
\hline 71 & 378 & 2,78 & 23 & V.508, M.280e, & F.I5 \\
\hline 72 & 379 & 2,36 & 25 & V.5 I0, M.283, & F.112/118 \\
\hline 73 & 380 & 2,86 & 23 & V.5I2, M.286s, & F.IOI \\
\hline 74 & 381 & 2,74 & 25 & V.5 I4, M.289f, & F.44/I4 \\
\hline 75 & 381 & 2,38 & 25 & V.5।4, M.289, & F.68 \\
\hline 76 & 383 & 2,04 & 23 & V.5 I7, M.297n, & F.56 \\
\hline 77 & 387 & 3,02 & 24 & V.533, M.3 IOj, & F.28 \\
\hline 78 & 388 & 2,82 & 24 & V.538, M.3। 3qq, & F.I I7 \\
\hline 79 & 389 & 2,82 & 24 & V.54I, M.316m, & F.35var \\
\hline 80 & 389 & 2,52 & 23 & V.54I, M.3 I 6jj, & F. 107 \\
\hline 81 & 389 & 3,46 & 24 & V.54I, M.3 I 6qq, & F.I 37 \\
\hline 82 & 389 & 2,98 & 25 & V.,M.3।6, & F.motivo borroso. \\
\hline 83 & 391 & 4,14 & 23 & V.549, M.320bb, & F.48var \\
\hline 84 & 391 & 2,56 & 24 & V.549, M.320, & F.93 \\
\hline 85 & 391 & 3,18 & 24 & V.567, M.320, & F.I06 \\
\hline 86 & 392 & 2,46 & 24 & V.569, M.3220, & F.27 \\
\hline
\end{tabular}




\begin{tabular}{|c|c|c|c|c|}
\hline 87 & 392 & 3,60 & 24 & V.569, M.322, \\
\hline 88 & 392 & 3,52 & 25 & V.569, M.322dd \\
\hline 89 & 392 & 3,14 & 24 & V.569, M.322kk, \\
\hline 90 & 393 & 2,06 & 24 & V.577, M.324f, \\
\hline 91 & 393 & 2,90 & 24 & V.577, M.324r, \\
\hline 92 & 394 & 2,76 & 24 & V.580, M.326f, \\
\hline 93 & 394 & 3,36 & 23 & V.580, M.326m, \\
\hline 94 & 394 & 2,80 & 24 & V.580, M.326m, \\
\hline 95 & 394 & 2,36 & 23 & V.580, M.326, \\
\hline 96 & 395 & 2,86 & 22 & V.58I, M.328d, \\
\hline 97 & 395 & 2,56 & 23 & V.58I, M.328d, \\
\hline 98 & 395 & 2,90 & 23 & V.58I, M.328, \\
\hline 99 & 396 & 2,80 & 25 & V.583, M.332, \\
\hline 100 & 397 & 2,16 & 22 & V.589, M.335d, \\
\hline 101 & 397 & 2,00 & 23 & V.590, M.335e, \\
\hline 102 & 397 & 3,20 & 24 & V.590, M.335n, \\
\hline 103 & 398 & 2,76 & 25 & V.592, M.338f, \\
\hline 104 & 398 & 2,48 & 24 & V.592, M.338f, \\
\hline 105 & $36 x$ & 2,62 & 23 & \\
\hline 106 & $38 x$ & 2,60 & 24 & \\
\hline 107 & $X X X$ & 2,14 & 24 & \\
\hline 108 & $X X X$ & 3,04 & 24 & \\
\hline
\end{tabular}

\section{Ceca Madinat Fās}

$\begin{array}{lllll}109 & 36 X & 2,34 & 22 & \\ 110 & 388 & 2,38 & 22 & \text { V.618, M.315b } \\ 111 & 394 & 2,90 & 24 & \text { V.634/636. Inédita. (Fig. 9) }\end{array}$

Esta pieza presenta en el anverso una distribución semejante a la Vives 634, mientras que en el reverso tiene la de la Vives 636. 395 $3,46 \quad 26 \quad$ V.639, M.330c

$113 \quad 39 x$

$2,58 \quad 24$

P2

Muhammad II (399-400/I008-1009)

\section{Ceca al-Andalus}

$\begin{array}{llllll}114 & 399 & 2,90 & 25 & \text { V.68I, M.340s, F.47 } \\ 115 & 400 & 2,60 & 25 & \text { V.689, M.342u, F.I } 85 \\ 116 & 400 & 2,88 & 25 & \text { V.688, M.342h, F.I } 44 \\ 117 & 400 & 3,00 & 25 & \text { V.688, M.342m, F.I } 64 \\ 118 & 400 & 3,58 & 24 & \text { V.684, M.342w, F.207 } \\ 119 & 400 & 3,62 & 25 & \text { V.69I, M.342mm, F. 58 }\end{array}$

Sulaymān (400// 009)

Ceca al-Andalus

$120 \quad 400 \quad 2,82 \quad 26 \quad$ V.69I, M.342ccc, F.97

\section{Ceca al-Zahrā}

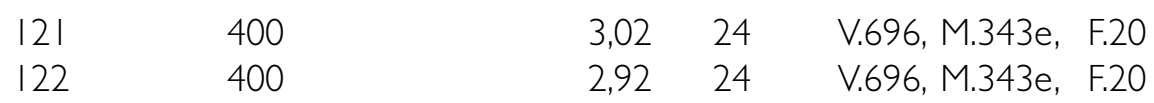




$\begin{array}{llllll}123 & 400 & 1,32 & 21 & \text { V.696, M.343e, } & \text { F.20 } \\ 124 & 400 & 4,16 & 23 & \text { V.696, M.343i, } & \text { F.24 } \\ 125 & 400 & 2,88 & 25 & \text { V.696, M.343i, } & \text { F.24 } \\ 126 & 400 & 3,10 & 24 & \text { V.696, M.343K, } & \text { F.32 }\end{array}$

Hišām II ( $2^{\circ}$ reinado) (400-403/I0। 0- I0/3)

\section{Ceca al-Andalus}

$\begin{array}{llllll}127 & 401 & 3,26 & 25 & \text { V.699, M.345d/o, F.30 } \\ 128 & 401 & 3,32 & 24 & \text { V.70I, M.345w/d, F.76 } \\ 129 & 402 & 2,82 & 24 & \text { V.703, M.346i, } & \text { F.5var } \\ 130 & 402 & 2,56 & 25 & \text { V.703, M.346i, } & \text { F. } 5 \\ 131 & 402 & 2,40 & 24 & \text { V.703, M.346, } & \text { F. } 23 \\ 132 & 402 & 3,36 & 24 & \text { V.703, M.346, } & \text { F.33 } \\ 133 & 402 & 2,20 & 24 & \text { V.703, M.346, } & \text { F.42 }\end{array}$

\section{Atribuidas a "gobernantes independientes" (Fig. 9) Ceca al-Andalus}
134
403
$2,62 \quad 24$
V.787, P.20b

Vives solo recogió seis ejemplares de este tipo (VIVES 1893, n 787, p. 494). La moneda de este hallazgo es diferente en sus cuños de la recogida por Prieto (PRIETO 1926, n²0b, p. I56).
135
$40(3 / 4)$
$3,10 \quad 26$
V.787/8, P.20b/c.

La lectura de la unidad en esta moneda es imposible al estar borrada; desde luego queda espacio entre la palabra "sanata" y la conjunción "waw" que la une con la centena, perfectamente legible. Su atribución a uno u otro año por criterios estilísticos o de semejanza de cuños no la hemos podido establecer, dado que el cuño de anverso es distinto de la n. 134, asi como de la I36, situación que se repite en el reverso.
136
404
$2,62 \quad 26$
V.788, P.20c

Vives solo cita una pieza de este tipo, en su colección (VIVES 1893, n 788, p. 494; PRIETO 1926,n²0c, p. I56). Suponemos que se trata de la misma moneda citada en ambos repertorios. La moneda número 136 de este hallazgo procede de la misma pareja de cuños, que la recogida por los autores mencionados.
137
404
$3,32 \quad 22$
Tipos V.80I y P.33.

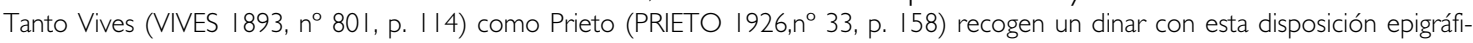
ca, debe tratarse de la misma moneda, depositada en la colección de la Academia de la Historia. La única referencia a un ejemplar de plata con este tipo la ha realizado Pellicer, citando material de una colección privada (PELLICER 1984, n²5, fot. n I2, p. 153-4). Corresponden a dos variantes decorativas diferentes al comparar la fotografía publicada con la aparecida en este hallazgo.
138
405
$2,76 \quad 22$
V.799, P.29.
139
405
$2,04 \quad 25$
V.799, P.29
R

Vives solo recogió dos piezas batidas a nombre de ibn Jalaf, una en el Mus. Arq. Nacional y otra en su colección (VIVES I893, n 799. p. I I3; PRIETO 1926, n² 29, p. 158). Estos dos ejemplares presentan cuños diferentes para los anversos y reversos. El cuño de anverso de la 138 es semejante a la recogida por Prieto.
140
405
$2,08 \quad 23$
V.792, P.32b.

Vives (VIVES I893, $n^{\circ} 792, \mathrm{p} .1 \mathrm{I}$ I), indica que es una pieza de cobre, mientras que Prieto (PRIETO 1926, n 32b, p. I58) la considera falsa; la pieza de este hallazgo no presenta ningun aspecto de falsedad y parece correcta.

Sulaymān $\left(2^{\circ}\right.$ reinado) $(403-407 / 1013-1017)$

\section{Ceca al-Andalus}

$\begin{array}{lllll}14 \mid & 404 & 2,58 & 24 & \text { V.796, P.28c (Fig. 9) } \\ 142 & (40) 4 & 1,64 & 23 & \text { V.796?, P.28c (Fig. 9) }\end{array}$




\begin{tabular}{|c|c|c|c|c|}
\hline 143 & 405 & 3,08 & 25 & V.797, P.28d \\
\hline | 44 & 405 & 2,18 & 24 & V.797, P.28d \\
\hline 145 & 405 & 3,38 & 24 & V.797, P.28d \\
\hline 146 & 405 & 2,64 & 24 & V.797, P.28d \\
\hline | 47 & 405 & 4,10 & 24 & V.797, P.28d \\
\hline 148 & 405 & 3,10 & 23 & V.797, P.28d \\
\hline 149 & 405 & 2,66 & 23 & V.797, P.28d \\
\hline 150 & 405 & 3,18 & 23 & V.797, P.28d \\
\hline$|5|$ & 405 & 2,92 & 24 & V.797, P.28d \\
\hline 152 & 405 & 2,72 & 24 & V.797, P.28d \\
\hline 153 & 405 & 2,98 & 24 & V.797, P.28d \\
\hline 154 & 405 & 2,88 & 24 & V.797, P.28d \\
\hline 155 & 405 & 3,22 & 24 & V.797, P.28d \\
\hline 156 & 405 & 2,58 & 22 & V.797, P.28d \\
\hline 157 & 405 & 2,44 & 25 & V.797, P.28d \\
\hline 158 & 405 & 3,96 & 25 & V.797, P.28d \\
\hline 159 & 405 & 2,26 & 24 & V.797, P.28d \\
\hline 160 & 405 & 2,32 & 24 & V.797, P.28d \\
\hline 161 & 405 & 2,78 & 24 & V.797, P.28d \\
\hline 162 & 405 & 3,90 & 24 & V.797, P.28d \\
\hline 163 & 405 & 2,94 & 23 & V.797, P.28d \\
\hline 164 & 405 & 3,58 & 24 & V.797, P.28d \\
\hline 165 & 405 & 2,30 & 23 & V.797, P.28d \\
\hline 166 & 405 & 2,88 & 25 & V.797, P.28d \\
\hline 167 & 405 & 3,38 & 25 & V.797, P.28d \\
\hline 168 & 405 & 2,96 & 23 & V.797, P.28d \\
\hline 169 & 405 & 3,16 & 23 & V.797, P.28d \\
\hline 170 & 405 & 2,82 & 23 & V.797, P.28d \\
\hline 171 & 405 & 2,70 & 23 & V.797, P.28d \\
\hline 172 & 405 & 4,14 & 25 & V.797, P.28d \\
\hline 173 & 405 & 4,50 & 25 & V.797, P.28d \\
\hline 174 & 405 & 2,96 & 24 & V.797, P.28d \\
\hline 175 & 405 & 3,32 & 24 & V.797, P.28d \\
\hline 176 & 405 & 2,16 & 23 & V.797, P.28d \\
\hline 177 & 405 & 2,36 & 23 & V.797, P.28d \\
\hline 178 & 405 & 2,98 & 23 & V.797, P.28d \\
\hline 179 & 405 & 2,82 & 23 & V.797, P.28d \\
\hline 180 & 405 & 3,48 & 25 & V.797, P.28d \\
\hline 181 & 405 & 2,72 & 23 & V.797, P.28d \\
\hline 182 & 405 & 3,40 & 24 & V.797, P.28d \\
\hline 183 & 405 & 3,26 & 24 & V.797, P.28d \\
\hline 184 & 405 & 3,26 & 24 & V.797, P.28d \\
\hline 185 & 405 & 2,92 & 23 & V.797, P.28d \\
\hline 186 & 405 & 2,66 & 23 & V.797, P.28d \\
\hline 187 & 405 & 2,58 & 25 & V.797, P.28d \\
\hline 188 & 405 & 2,54 & 26 & V.797, P.28d \\
\hline 189 & 405 & 2,96 & 25 & V.797, P.28d \\
\hline 190 & 405 & 2,56 & 24 & V.797, P.28d \\
\hline 191 & 405 & 2,26 & 25 & V.797, P.28d \\
\hline 192 & 405 & 3,78 & 25 & V.797, P.28d \\
\hline 193 & 405 & 3,32 & 24 & V.797, P.28d \\
\hline
\end{tabular}




$\begin{array}{lllll}194 & 405 & 2,64 & 24 & \text { V.797, P.28d } \\ 195 & 405 & 2,10 & 23 & \text { V.797, P.28d } \\ 196 & 405 & 2,90 & 24 & \text { V.797, P.28d } \\ 197 & 405 & 3,54 & 25 & \text { V.797, P.28d } \\ 198 & 405 & 3,66 & 24 & \text { V.797, P.28d } \\ 199 & 405 & 2,78 & 24 & \text { V.797, P.28d }\end{array}$

Hišām II Cobre forrado

$\begin{array}{llll}200 & X X X & 1,90 & 25 \\ 201 & X X X & 1,48 & 21\end{array}$

\section{BIBLIOGRAFÍA}

AGUIRRE SÁDABA, F.J., JIMENEZ MATA, Mª C.,(1979): Introducción al Jaén islámico, Jaén.

CANO ÁVILA, P., (1993): "Dirhemes califales hallados cerca de Alcaudete (Jaén)". III Jarique de Numismática Hispano-Arabe, Madrid pp. 299-312.

CANTO GARCÍA, A., (1986): "La reforma monetaria de Qasim", Al-Qantara, VII, pp.403-428.

CANTO GARCÍA, A., (1987): "Los Ashab as-Sikka de Abd al-Rahman IIIi?", Cuadernos de Prehistoria y Arqueología de la Universidad Autónoma de Madrid 17, pp.3I5-329.

CANTO GARCÍA, A., (1990): "Un hallazgo de moneda hispano-árabe de la Colección Santa-Olalla", Cuadernos de Prehistoria y Arqueología de la Universidad Autónoma de Madrid 17, pp.315-329.

CANTO GARCÍA, A.; PALOU, F.; TORTAJADA, B., (1988): "Volumes of production of dirhams in al-Andalus during the years A.H. 330 and A.H. 340 as calculated fron die-link statistics." Problems of Medieval Coinages in the Iberian Area, vol. 3, pp. 91-98.

CARDITO, L.; MARTÍNEZ, C.; SEVILLA, C., (1988): "Un hallazgo de moneda islámica en Baena (Córdoba)", II Jarique, pp. 286-287.

CARMONA, R.; LIROLA, J. y PUERTAS, J.M, (1993): "El tesorillo de dirhames de Los Lobicos (Priego de Córdoba): una muestra de las acuñaciones de moneda califal omeya andalusí," Antiqvitas, n 4,pp. 67-80.

CARTER, G.F. (1984): "Numismatic Calculations from DieLink Statistic, M.Góems Marques (ed.) Problems of Medieval Coinage in the Iberian Area," Santarem, pp.9|-I04. CODERA, F., ( 1875$)$ : "Tesoro de monedas árabes," Revista de Archivos Bibliotecas y Museos, pp. 341-45.

CODERA, F., ( 1878): "Títulos honoríficos y nombres propios en las monedas arábigo-españolas," Revista Universidad de Madrid, Separata Madrid, Aribau y Compañía, 86 pp.

CODERA, F.,(1880): "Tesoro de monedas árabes descubierto en Zaragoza", Museo Español de Antigüedades, vol. Xl, pp. 299-315, I lám.
CODERA,F.,(I 882): "Monedas árabes adquiridas par el Museo Arqueológico Nacional en Córdoba y Sevilla por Don Francisco Codera en el año 1877, "Anuario del Cuerpo Facultativo de Archiveros, Bibliotecarios y Anticuarios, pág. 379.

CODERA, F.,( I 884): "Tesoro de monedas árabes descubiertas en Zaragoza," Boletín de la Real Academia de la Historia, tomo IV, pp. 312-319.

CODERA, F.,(I 893): "Tesoro de monedas árabes descubierto en la provincia de Cuenca," Boletín de la Real Academia de la Historia, tomo XXII, pp. 433-438.

CODERA, F.,(1897): "Tesoro de monedas árabes descubierto en Belalcázar," Boletín de la Real Academia de la Historia, tomo XXXI, pp. 449-457.

DOMENECH BELDA, C., (1990): "El hallazgo de dirhames califales de Almoradi (Alicante)," Gaceta Numismática 97-98, pp. 129-134.

FERNÁNDEZ PUERTAS, A., (1982): "Catálogo de los fondos numismáticos hispano-musulmanes del Museo de Cuenca," Cuademos de la Alhambra, 18.

FROCHOSO SÁNCHEZ, R., (1996): "Las monedas califales de ceca al-Andalus y Madinat al-Zahra," Caja Sur Publicaciones.

GOMES MARQUES, M., (1988): "Técnicas modernas de investigaçao en numismática," I Jarique de Estudios Numismáticos Hispano-Arabes, Zaragoza, pp. I 05- 139.

LAFUENTE VIDAL, J., ( 1930): "El tesoro de monedas árabes de Elche," Boletín de la Real Academia de la Historia, tomo XCVI, pp. 846-856, Madrid.

LLOBREGAT, E., (1976): "Un hallazgo de dirhams califales en el término de Almoradí (Alicante)", Numisma, $n^{\circ}$ |38-143, pp. 225-228.

MARTíNEZ, A. (1989): "El tesoro califal de "Los Villares" (Caudete, Valencia)." Acta Numismática vol. 17-18, pp. 177-197.

MARTíNEZ SALVADOR, C. (1992): "Los Ashab al-Sikka" en las acuñaciones de Hisam II", Cuadernos de Prehistoria y Arqueología de la Universidad Autónoma de Madrid 19 , pp.421-433. 
MEDINA GOMEZ, A., (1992): Monedas Hispano-Musulmanas. Toledo.

MILES, G., (1960): "The Coinage of the Umayyads of Spain, New York," The American Numismatic Society, 2 vols.

NAVARRO OLTRA, V.C, (I99|): "Troballa de dirhems califals a Baena (Córdoba)", anys 330-400 H, Gaceta Numismática 103, pp 7-15.

NAVASCUÉS, J. Ma de, (1958): "Tesorillo de monedas de plata del califato cordobes y fatimies," Numario Hispanico, 7 , pp.207-210.

NAVASCUÉS, J. Ma de,(196 la): "Tesoro árabe de la calle Cruz Conde," Numario Hispánico, tomo X, pp. I70-I72.

NAVASCUÉS, J. Ma de,(196 lb): "Tesoro árabe de la calle Cruz Conde (Córdoba)," Memorias de los Museos Arqueológicos Provinciales, 1958-61, pp.79-81.

NAVASCUÉS, J. Ma de, (|96|): "Tesoro de Cihuela (Soria)," Memorias de los Museos Arqueológicos Provinciales, 19586I, pp.8I-83.

NAVASCUÉS, J Ma de, (|96|): "Tesorillo de moneda califal," Numario Hispanico, 10, pp. 169-170.

NAVASCUÉS,J.de, (1957): "Tesoro hispano-arabe hallado en Trujillo (Cáceres)", Numario Hispanico, 6, pp.5-28.

NAVASCUÉS, J. de, (1958): "Tesorillo de monedas de plata del califato cordobés y fatimíes," Numario Hispánico , 7, pp. 207-210.

NAVASCUÉS,J. de,(|96|): "Tesoro de Cihuela (Soria)", Numario Hispánico , 10, pp. 173-175.

PELLICER I BRU, J., (1982): "Un tresor de dirhems àrabs a S.C.-J.", Acta Numismática, n 12, pp. 139-165.

PELLICER I BRU, J., (1984): "Suleiman Al-Mostain 400I010/407-1014," Acta Numismática, vol. 14, pp. I43-160.

PELLICER I BRU, J., (1985): "El tresoret de moneda àrab LR-P, del anys 331-4I8A.H," Acta Numismática, vol. I5, pp. I57-I80.

\section{RESUMEN}

El artículo presenta un hallazgo de monedas califales Omeyas de Córdoba con una presencia especial de monedas del último califa Sulaymān al Musta'in halladas en una excavación arqueológica en la ciudad de Jaén. La rareza de las piezas mencionadas así como la complejidad del momento histórico han sugerido la realización de estudios de cuños para determinar una estimación sobre el volumen de moneda emitida a nombre del citado califa en un periodo concreto de los años finales de su reinado.

PALABRAS CLAVE: Al-Andalus, califato, numismática, hallazgos, Jaén, estudio de cuños.
PELLICER I BRU, J., (1987): "AL-ANDALUS. Estudio de cuños diferenciados de la ceca de Madinat al-Zahara y estimación de las acuñaciones de moneda (Años 34035 I=95 |/2-962/3)". (Actes Colloque Int. Rythmes de la production monétaire de I'antiquité a nous jours. eds. G. Depeyrot; T. Hackens; G. Moucharte). Univ. catholique Lovaine, Numismatica Lovaniensia, 7, pp. 425-432.

PINERO JIMÉNEZ, F.; MARTÍNEZ ROMERO, J., ( 1954): "Monedas árabes halladas en Jimena, Jaén," Boletín del Instituto de Estudios Giennenses, n 5, pp. 89-94.

PRIETO Y VIVES, A., (19|4): "Hallazgo de monedas hispano-musulmanas," Revista de Archivos, Bibliotecas y Museos, $3^{\text {a }}$ etapa, tomo $X X X 1$, pp. 362-367.

PRIETO Y VIVES, A., (19|5): "Nuevo hallazgo de monedas hispano-musulmanas," Revista de Archivos, Bibliotecas y Museos, $3^{\mathrm{a}}$ etapa, tomo $X X X 11,30$ pp.

PRIETO Y VIVES, A., (1926): Los Reyes de Taifas. Madrid.

PRIETO Y VIVES, A., (1934): "Tesoro de monedas musulmanas encontradas en Badajoz," Al-Andalus, vol. II, pp. 299-327, con ilustr.

RUIZ ASENSIO, J.M.,(1962): "Tesorillo de dirhems del califato hallados en Jaén," Boletín del Instituto de Estudios Giennenses, pp. I-26

SÁENZ DÍEZ, J.I., (1984): Las acuñaciones del califato de Córdoba en el Norte de Africa, ed. Vico\&Segarra, Madrid.

SÁENZ DÍEZ, J. I.; PELLICER I BRU, J., (1986): "Análisis de cuños de dirhems del H.392 de al-Andalus" (I00I1002 d.C.), Acta Numismática, vol. I6, pp. 1 27-| 40.

SERRANO, J. L. (1997): "Un complejo califal de Marroquíes Bajos (Jaén)". Arqueología y Territorio Medieval, 4, pp. 59-79.

VIGUERA, Mª.J. (1994): "Los reinos de Taifas. Al-Andalus en el siglo XI," Historia de España de Menendez Pidal, Madrid.

VIVES Y ESCUDERO, A., ( 1893): Monedas de las dinastías arábigo-españolas, Madrid, (Reed. J. Cayón, Madrid, 1978).

\section{ABSTRACT}

The paper deals with a hoard of umayyad caliphal coins with a special bias in the coins from Sulaymān al Musta in, the last of the caliphs from Cordoba, found in archaeological excavations in Jaén. The scarcity of the pieces and the complexity of the historical situation has suggested the suitability of a die-study to estimate the volume of coin's issue (with the name of Sulayman) in the last years of his kingdom.

KEY WORDS: Al-Andalus, caliphate, numismatics, hoards, Jaen, die-study. 


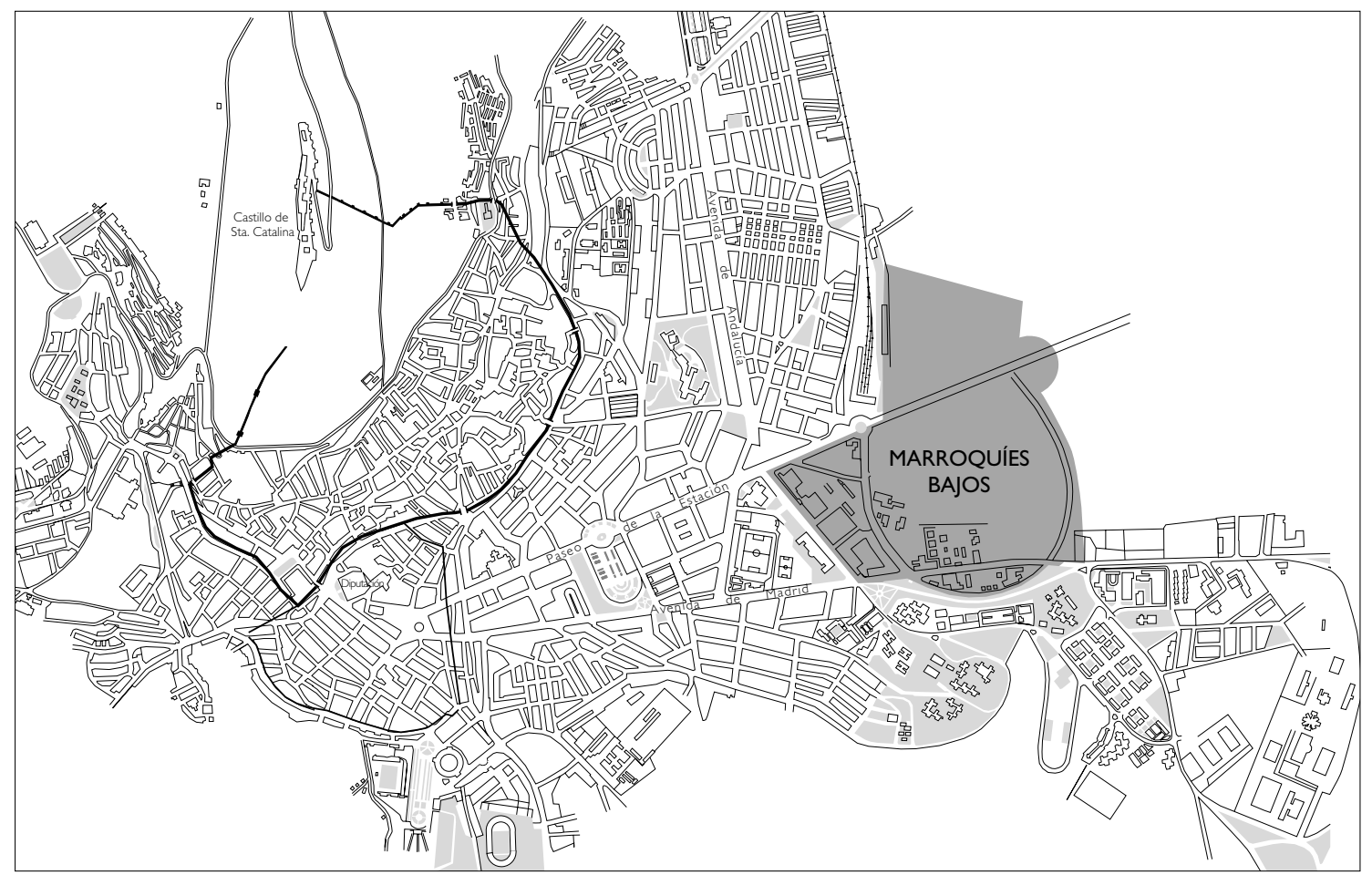

Fig. I. Plano de situación.

Fig. 2. Ubicación del solar.

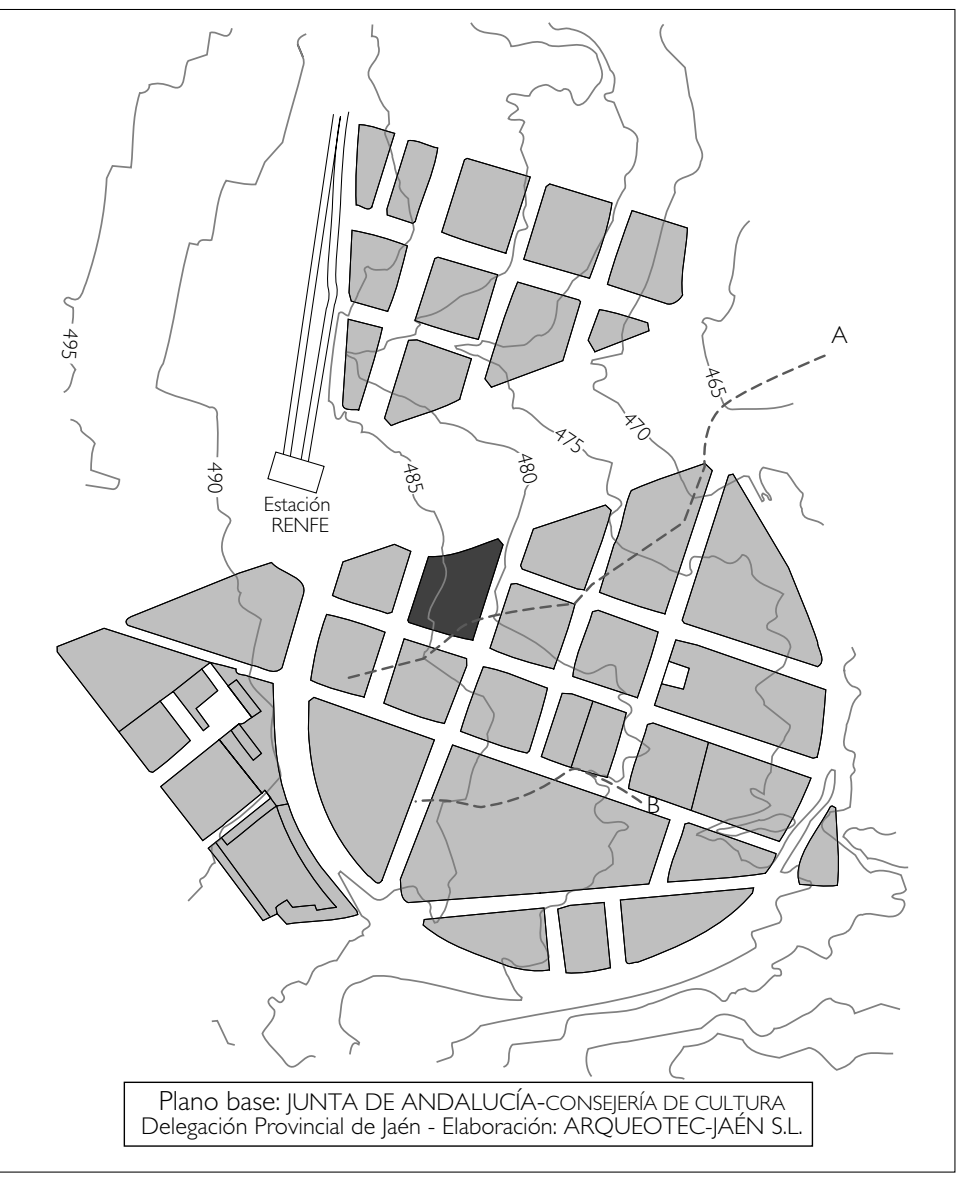




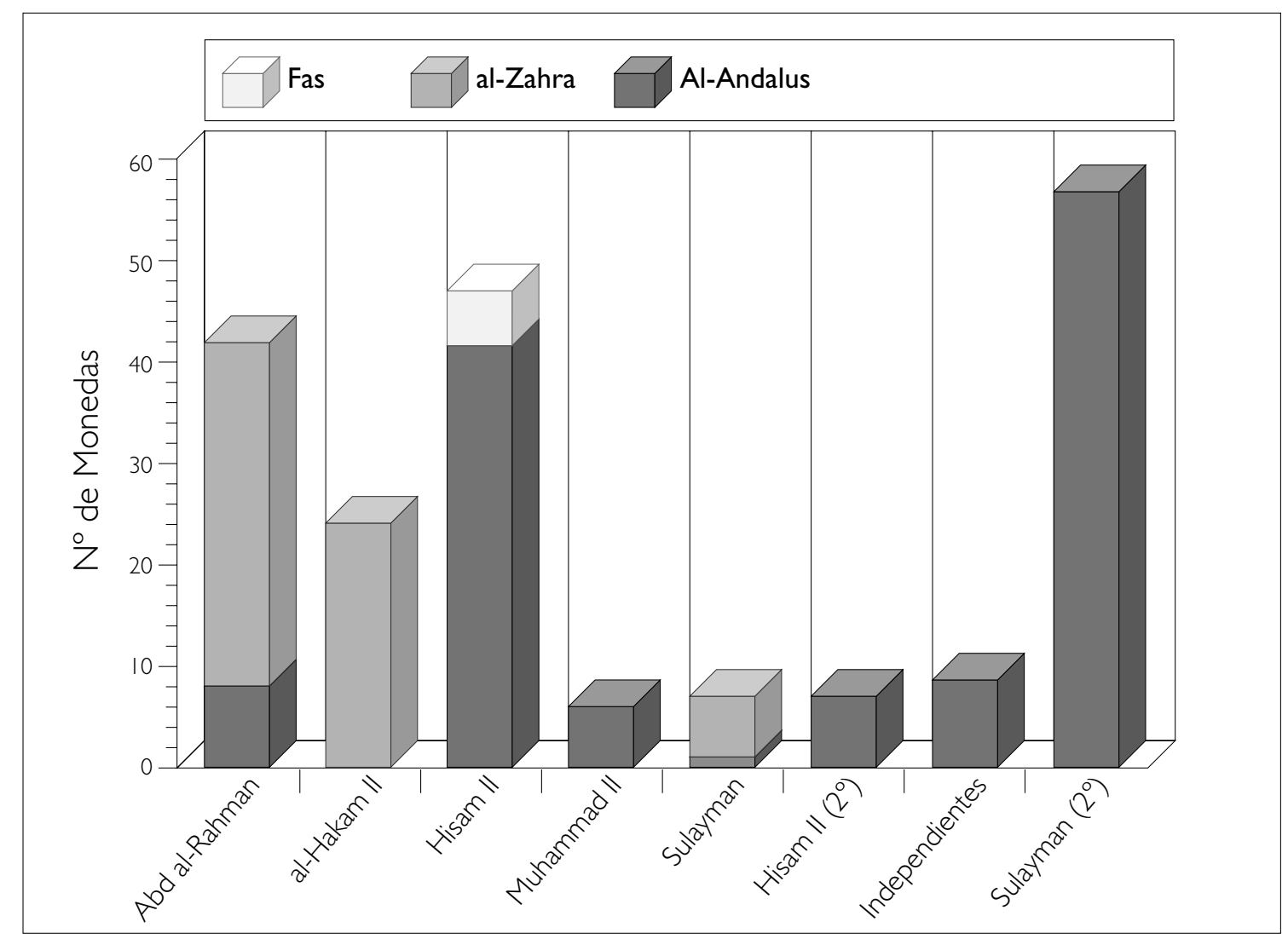

Fig. 3.I. Distribución de monedas por califa y ceca.

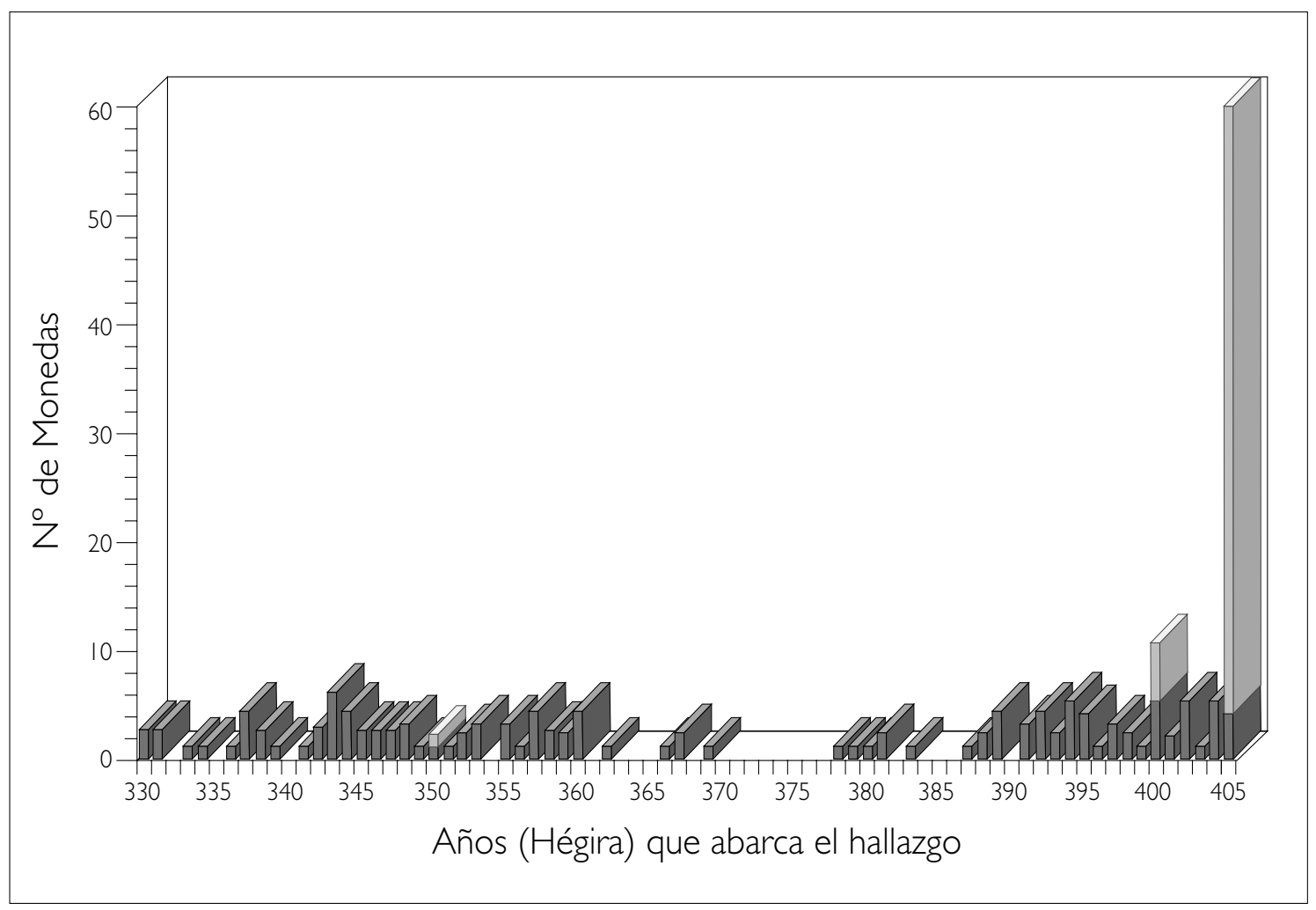

Fig. 3.2. Número de monedas distribuidas por años. 


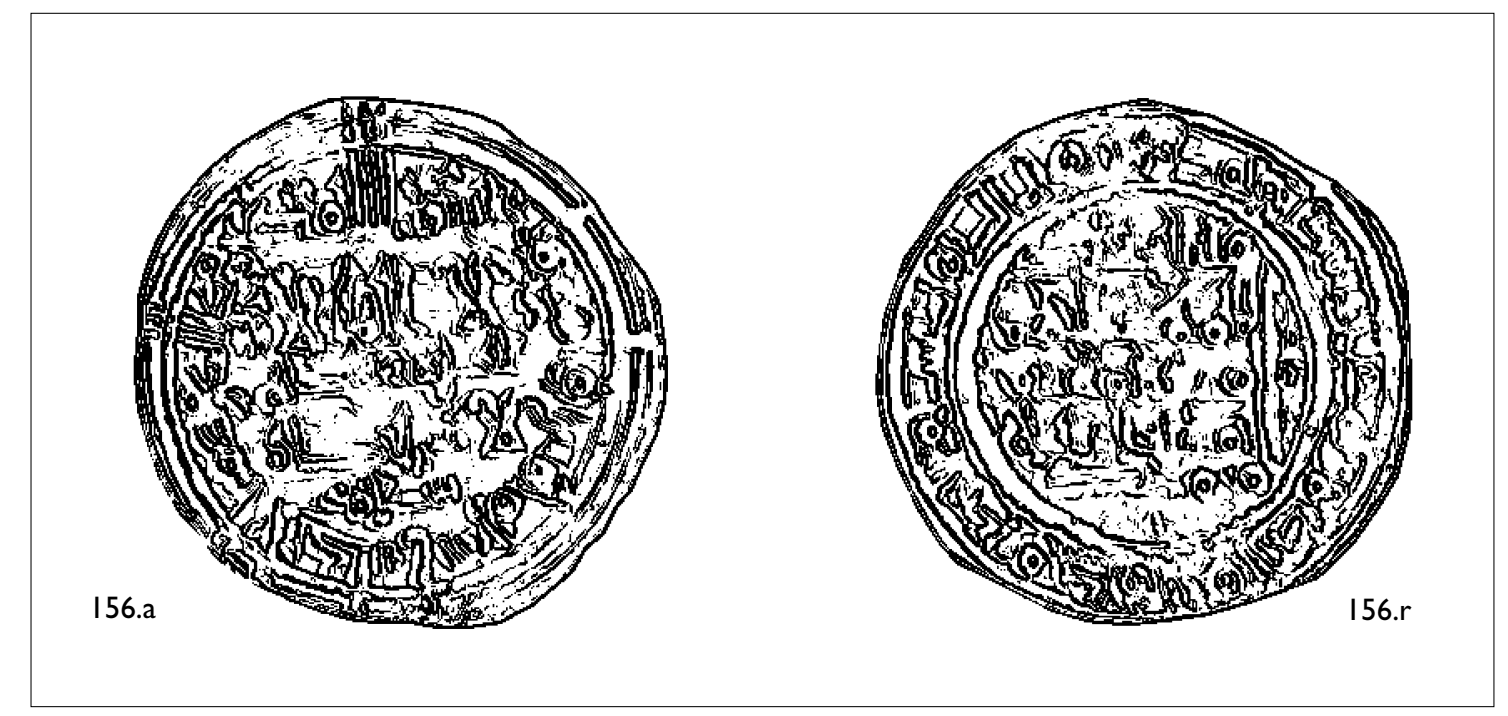

Fig. 4. Reconstrucción de bordes.

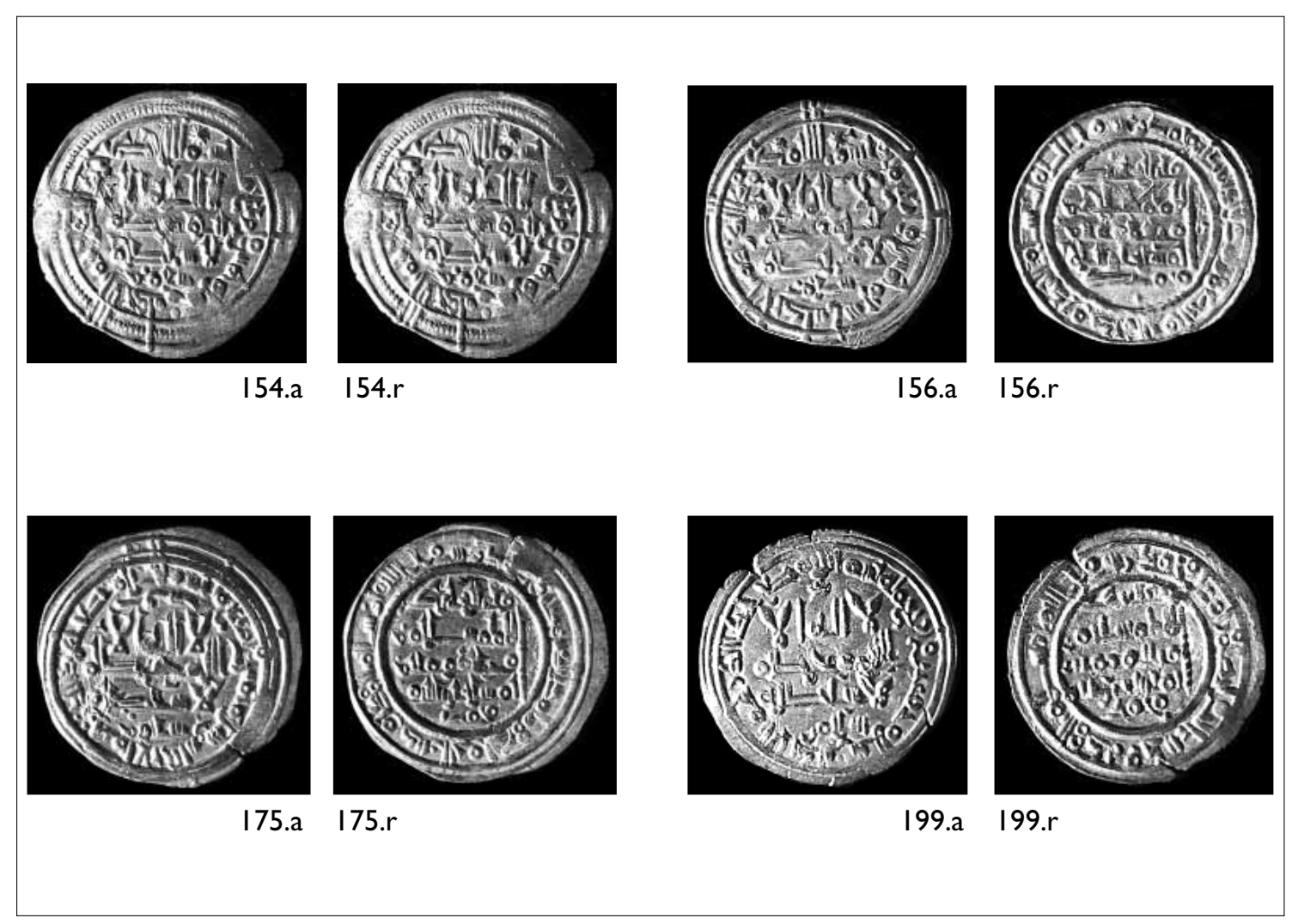

Fig. 5. Tipos de Sulaymān. 


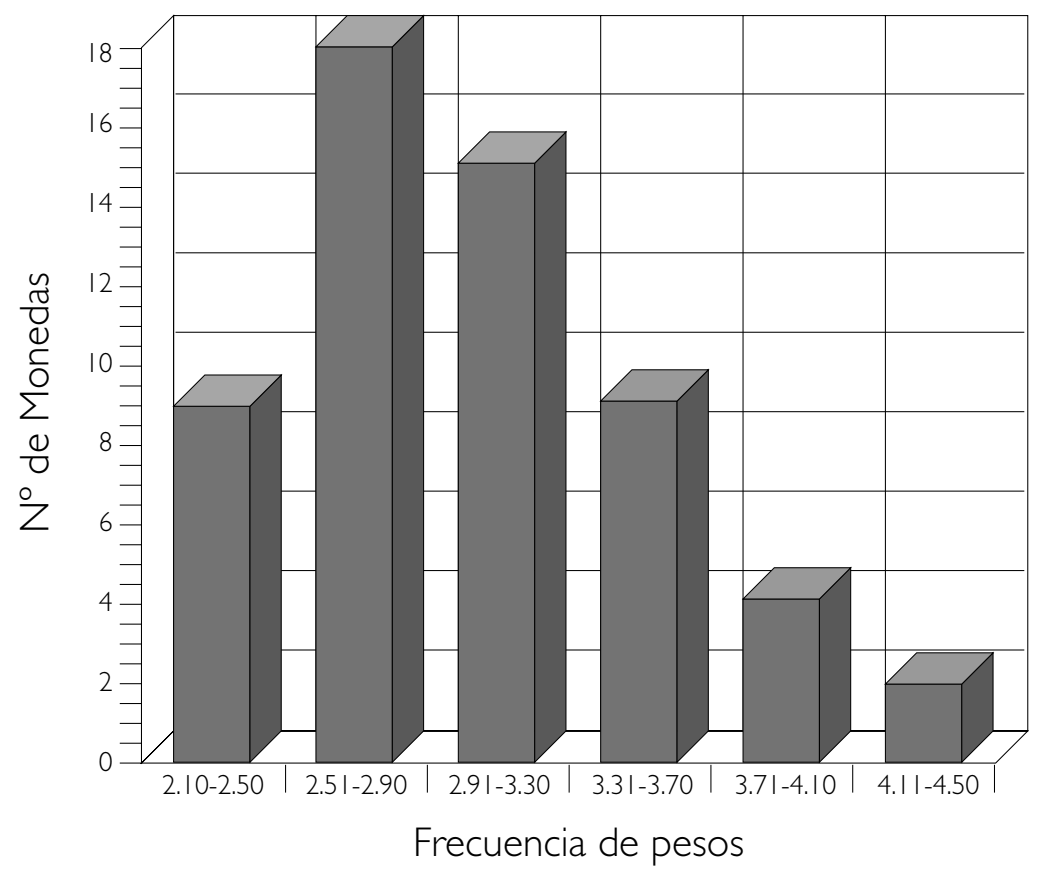

Fig. 6. Monedas de Sulaymān del año 405H. ordenadas por pesos.

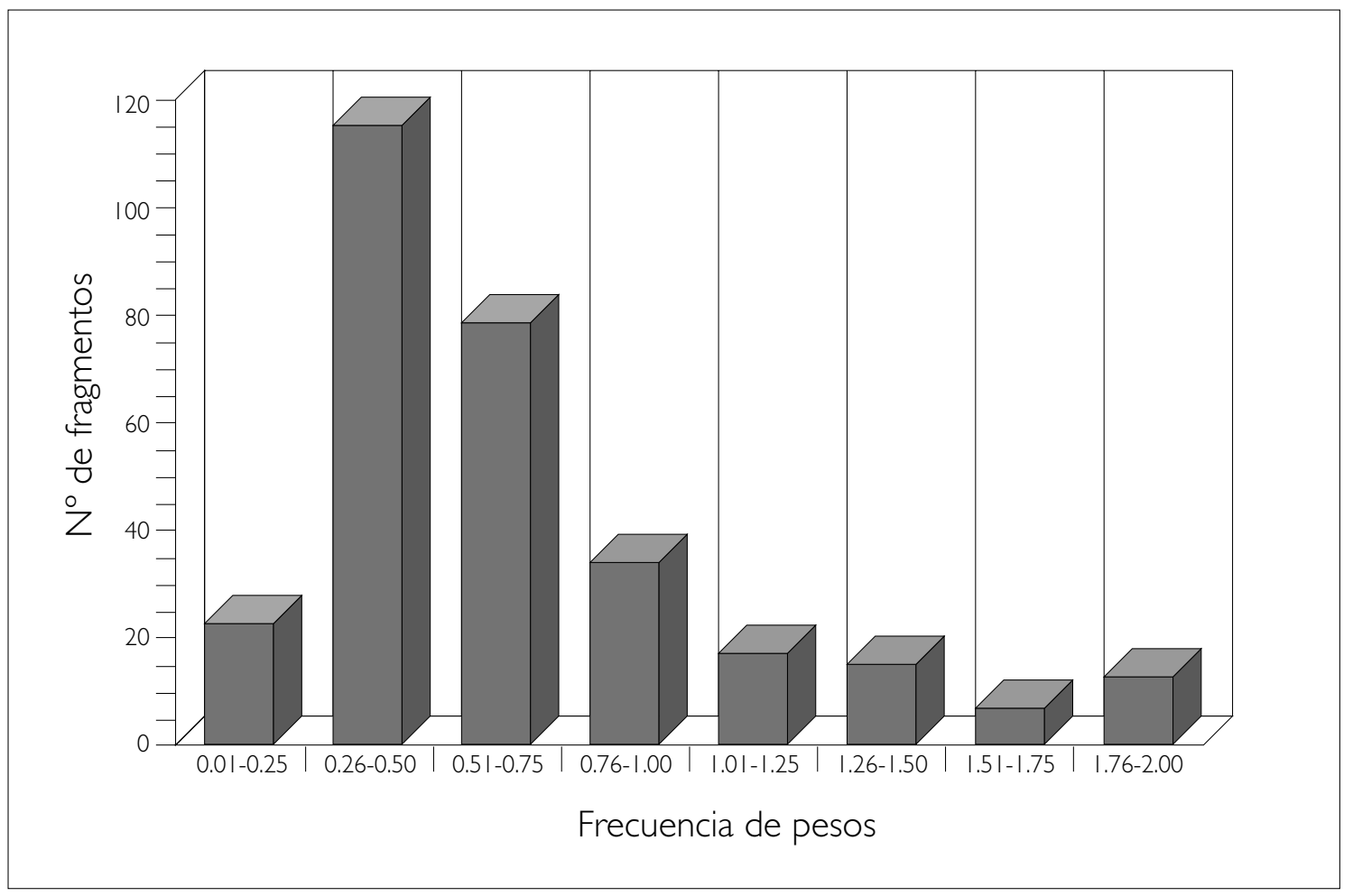

Fig. 7. Fragmentos distribuidos por frecuencias. 


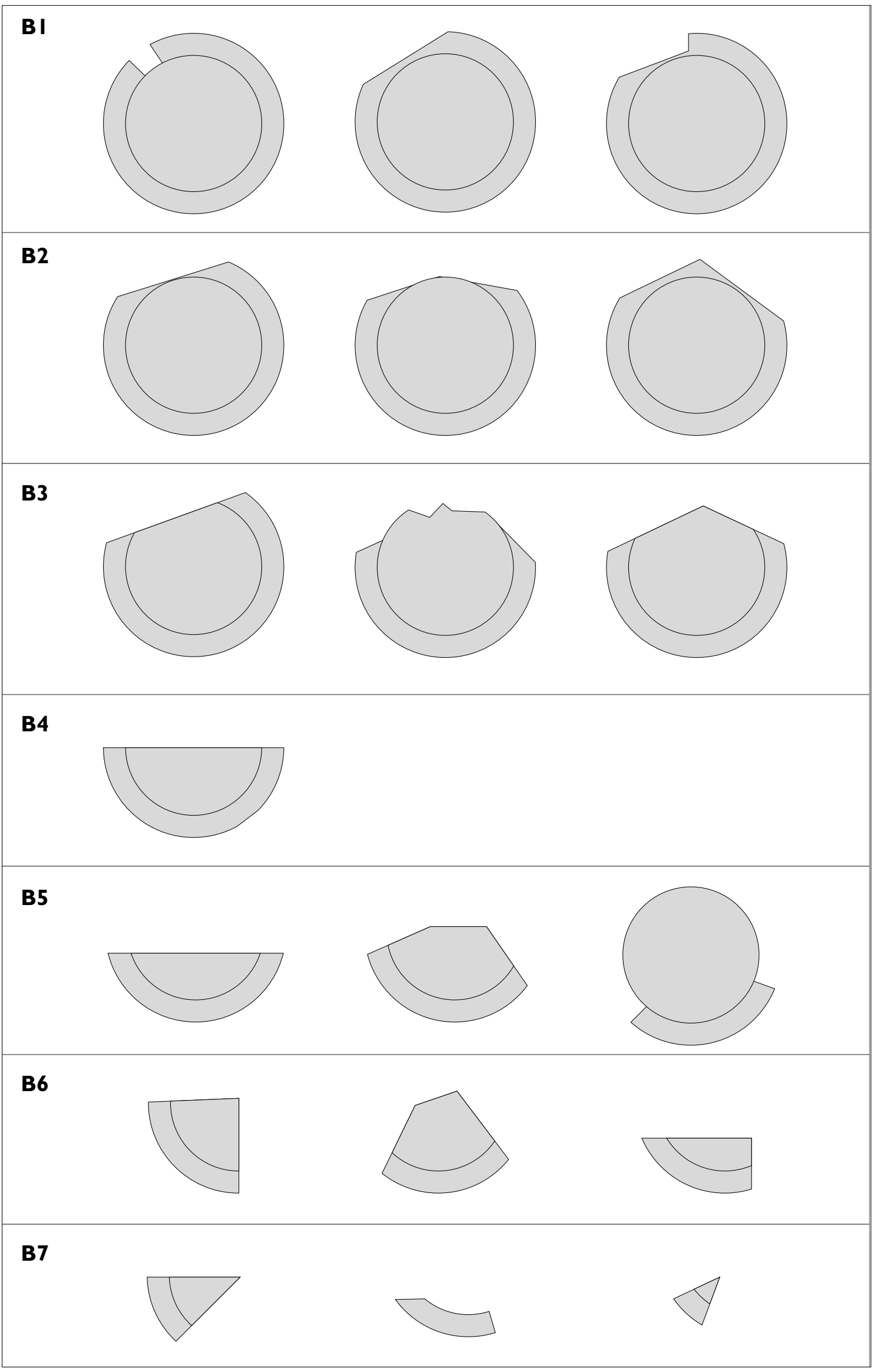

Fig. 8. Tipos de cortes. 

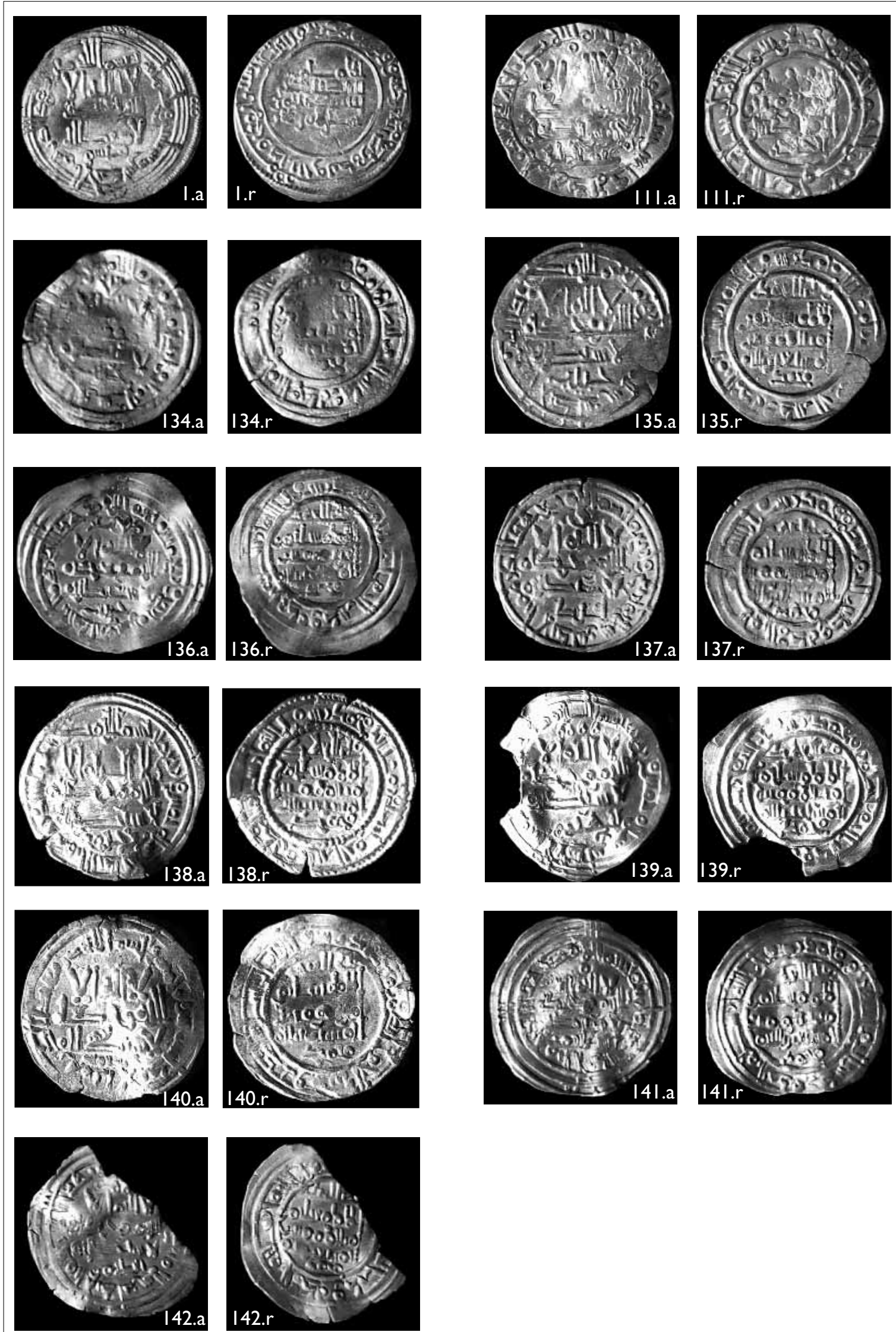

Fig. 9. Ejemplares inéditos y de los gobernadores independientes. 